Sc Miroslav Stojanović, pukovnik, dipl. inž. Milan Milovanović, potpukovnik, dipl. inž. Aleksandar Janković, dipl. inž. Vojnomedicinska akademija Beograd

\section{REALIZACIJA RAČUNARSKE MREŽE VOJNOMEDICINSKE AKADEMIJE}

UDC: $004.738 .4: 355.721(497.1)$

Rezime:

Vojnomedicinska akademija (VMA) u Beogradu danas se ne može zamisliti bez kvalitetnog informacionog sistema, koji se najčešće razvija u sistemu računarske mreže. Cilj ovoga rada je da prikaže smernice $i$ definiše neka rešenja u implementaciji buduće računarske mreže VMA. Težište rada je na implementaciji prva tri nivoa OSI modela jedne složene $i$ kompleksne mreže kakva bi trebalo da bude računarska mreža VMA.

Ključne reči: informacioni sistem, računarska mreža, projektovanje, softver, Web.

\title{
MEDICAL MILITARY ACADEMY INFORMATION SYSTEM MENAGEMENT
}

Summary:

The Medical Military Academy (MMA) in Belgrade cannot be imagined without a highquality information system implemented in a corresponding computer network. The aim of this study is to show guidelines and possible solutions in implementing a computer network in to the MMA in the future. The main part of this study describes the implementation of the first three levels of the OSI model into the complex MMA computer network.

Key words: information system, computer network, design, software, Web.

\section{Uvod}

Kada se projektuje infrastruktura jedne računarske mreže mora se uzeti u obzir više zahteva. Neki od njih su: broj korisnika u sistemu (broj priključaka, prostorni raspored priključaka i organizacionih jedinica), karakteristike saobraćaja u sistemu (karakteristike mrežnih aplikacija i zahtevi koje te aplikacije postavljaju pred mrežu), protokoli koji će biti implementirani, veze koje je potrebno ostvariti sa drugim sistemima i slično. Da bi se ovi zahtevi ispunili potrebna je saradnja na svim nivoima u okviru VMA u funkciji definisanja projektnog zadatka mrežne infrastrukture i informacionog sistema $\mathrm{u}$ celini. Pošto takav zadatak ne postoji, ovaj rad definiše neke osnovne principe implementacije, polazeći od opštih karakteristika ustanove, njene organizacije i delatnosti kojom se bavi. U skladu s tim predložena su rešenja realizacije mreže, ali se ona mogu korigovati, u zavisnosti od konkretnih zahteva, ali uvek sa jasno definisanim principima. Ipak, neka konkretna rešenja, kao što je realizacija kičme same mreže, prikazana su u ovom radu. 


\section{Opšta struktura mreže}

Vojnomedicinska akademija je ustanova sastavljena od klinika i instituta koji su nosioci osnovne delatnosti ustanove, i administrativnih organa koji se sastoje od pratećih službi neophodnih za uspešno funkcionisanje celog sistema. Svaka od ovih celina ima svoje specifične funkcije i zadatke, pa u skladu s tim i različite potrebe prema odgovarajućem informacionom sitemu. Pored toga, postoji i potreba za međusobnom razmenom informacija između pojedinih delova sistema. Naravno, svaki od ovih sistema ima potrebu da vrši razmenu informacija sa „spoljnim svetom“.

Ako se ovakva organizacija VMA prenese na strukturu računarske mreže neophodne za implementaciju informacionog sistema, dolazi se do zaključka da mreža, takođe, mora da bude hijerarhijski organizovana. Hijerarhijska struktura podrazumeva da se mreža sastoji od logičkih celina, koje odgovaraju organizacijskim jedinicama VMA. Svaka od ovih logičkih celina je mreža za sebe, koja je projektovana u svemu prema funkcijama organizacione jedinice u kojoj je implementirana. Na osnovu toga, implementacija računarske mreže može se sagledati u dva osnovna dela. Prvi deo čine računarske mreže samih klinika, instituta $\mathrm{i}$ adminstrativnih organa VMA, dok drugi deo čini jezgro same mreže, tj. mrežni backbone koji omogućava međusobno povezivanje klinika i instituta u jednu, jedinstvenu mrežu. Ova dva dela mreže opisana su pojedinačno $u$ narednim poglavljima.

Polazeći od OSI modela sve funkcije na mreži mogu se podeliti u sedam ni- voa. U ovom radu prikazana je realizacija mreže na prva tri nivoa OSI modela, tj. na fizičkom nivou, nivou prenosa podataka i mrežnom nivou. Zahvaljujući svojoj popularnosti, širokoj rasprostranjenosti i fleksibilnosti TCP/IP stek protokola nameće se i rešenje za implementaciju prva četiri nivoa računarske mreže. U skladu s tim, u ovom radu je prikazana sledeća realizacija mreže: na prvom i drugom nivou opisana je Ethernet struktura mreža, dok je na trećem nivou implementiran IP protokol.

Logičke celine u mreži predstavljaju posebne virtuelne Lanove u sistemu, tj. posebne podmreže. Svaka od ovih celina ima različit broj računara, pa je, u skladu s tim, potrebno svakom delu dati odgovarajući opseg IP adresa.

Računarske mreže klinika predstavljaju, posmatrajući celokupnu računarsku mrežu VMA, pristupnu i distributivnu ravan jedne kompleksne računarske mreže. Naravno, na klinikama će biti primenjena različita rešenja, ali je princip koji je ovde izložen uvek isti. Kada je u pitanju mrežna kičma, u radu je dato konkretno rešenje njene realizacije.

\section{Mreže klinika}

Osnovna zamisao jeste da se računarska mreža VMA implementira u dva dela. Prvi nivo predstavljaju računarske mreže organizacionih jedinica VMA, t $\mathrm{j}$. klinika, instituta $\mathrm{i}$ administrativnih organa. Ove računarske mreže treba implementirati tako da se na njima uspešno mogu izvršavati aplikacije neophodne za uspešno funkcionisanje samih klinika, ali $i$ da omoguće povezivanje klinika u jedinstvenu mrežu VMA. 
Opšta šema računarske mreže jedne klinike prikazana je na slici 1 . Kao što se uočava, mreža ima dve osnovne ravni. Prvu ravan predstavljaju Layer 2 switchevi na koji se povezuju radne stanice, štampači, medicinski aparati sa Ethernet portovima, IP kamere, uređaji za bežični pristup, i sl. Drugi nivo predstavlja Layer 3 switch na koji se povezuju Layer 2 switchevi prethodne ravni. Ovaj switch omogućava međusobno povezivanje Layer 2 switcheva sa jedne strane i povezivanje celokupne mreže klinike na kičmu mreže sa druge strane.

Layer 2 switchevi treba da zadovolje sledeće uslove:

- dovoljan broj portova za povezivanje računara i ostalih uređaja;

- upravljivost, tj. mogućnost upravljanja i konfigurisanja mreže. Ovaj zahtev je značajan za buduće administratore mreže, jer im omogućava da se sa jedne lokacije upravlja mrežnim uređajima;
- implementacija virtuelnih LAN-ova (VLAN). Ova osobina omogućava da se mreža segmentira na logičke celine, tako da komunikacija između računara $\mathrm{u}$ jednom VLAN-u ne ugrožava računare $u$ drugom. To je bitno sa stanovišta bezbednosti na mreži. Da bi komunikacija između VLAN-ova ipak bila moguća, u aplikacijama koje to zahtevaju, Layer 3 switch omogućava rutiranje paketa koji potiču iz različitih VLAN-ova. Zbog toga agregatni portovi na switchu tj. portovi ka Layer 3 switchu treba da budu konfigurisani tako da podržavaju standard 802.1.q. Ovim standardom definiše se tzv. Virtual Bridged $L A N$ arhitektura, servisi, protokoli i metode kojima se implementira QoS. Ovim standardom se LAN mreža može podeliti - premostiti na nekoliko nezavisnih segmenata koji se odvojeno mogu posmatrati kao posebne LAN;

- implementacija QoS (Quality of Service), korišćenjem standarda 802.1. p, pruža mogućnost davanja prioriteta poje-

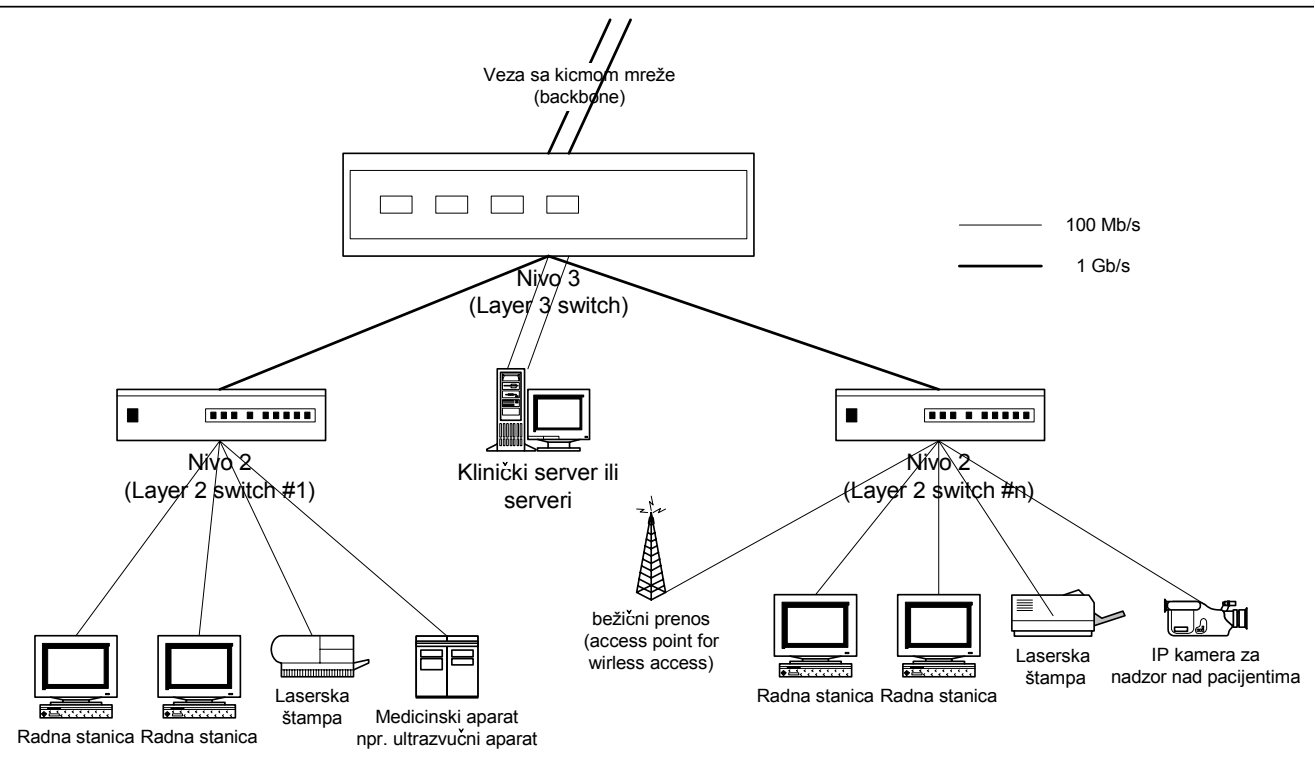

Sl. 1 - Opšta struktura računarske mreže jedne organizacione celine VMA 
dinim paketima na mreži. Odgovarajućim korisnicima, odosno aplikacijama, rezerviše se dogovoreni propusni opseg, u slučaju zagušenja na mreži. Korisnicima sa nižim prioritetom može se čak i prekinuti prenos, kako bi se održao ugovoreni kvalitet servisa prioritetnim korisnicima. To je naročito bitno za glasovne i video aplikacije na mreži koje su naročito osetljive na gubitke paketa u mreži i kašnjenje, pa je to jedan od načina da se ti problemi reše. S obzirom na to da računarska mreža VMA treba da obuhvati prenos slike i glasa, ovaj uslov je važan u njenoj implementaciji.

Layer 3 switch treba da zadovolji iste uslove kao i prethodni, i još sledeće:

- rutiranje paketa između različitih VLAN-ova;

- kompatibilnost sa standardom 802.1q i 802.1p, čime se opisuju najvažnije metode za uspostavljanje QoS na MAC nivou TCP/IP modela mrežne arhitekture, kao što su klase saobraćaja i dinamičko filtriranje;

- mogućnost implementacije link agregation grupa (LAG), tj. mogućnost da se više fizičkih linkova ugradi u jedan logički link, što omogućava veći kapacitet. To je važno, jer veze ka serverima na klinici, naročito ka onim serverima koji su najviše opterećeni, treba da budu implementirane na ovaj način, jer se pored povećanja kapaciteta omogućava i redundantnost serverske veze ka mreži (na slici 1 prikazano dvostrukom vezom od servera ka switchu). Ova osobina može biti interesantna i za interswitch povezivanje.

Kapaciteti linkova u mreži odabrani su tako da zadovolje sve potrebne zahteve za propusnim opsegom, a uzimajući u obzir karakteristike samog saobraćaja u mre- ži. Naime, polazi se od pretpostavke da će se više od polovine saobraćaja, koji se generiše u samoj mreži neke klinike, u njoj i terminirati. Naime, manji deo saobraćaja biće odlaznog karaktera, tj. namenjen drugim klinikama, odnosno centralnim serverima na VMA. Kapaciteti linkova od switcheva do računara su $100 \mathrm{Mb} / \mathrm{s}$. Ovi linkovi treba da budu realizovani UTP kablovima najmanje kategorije 5e. Implementacija kablovima ove kategorije omogućava kasnije i prelazak na gigabitni ethernet u pristupnoj ravni, bez upotrebe optičkih kablova. Linkovi između Layer 2 i Layer 3 switcheva su kapaciteta $1 \mathrm{~Gb} / \mathrm{s} \mathrm{i}$ mogu se realizovati upotrebom multimodnih optičkih vlakana. Implementacija gigabitnih linkova optičkim vlaknima omogućava, u budućnosti, nadogradnju sistema na $10 \mathrm{~Gb} / \mathrm{s}$ vezu promenom modula na aktivnoj opremi bez ulaganja $\mathrm{u}$ fizičku infrastrukturu. Pored toga, upotreba optičkih vlakana omogućava veze između switcheva na većim rastojanjima od onih koja se mogu postići upotrebom UTP kablova. Link prema kičmi mreže naročito je značajan, jer predstavlja vezu klinike sa ostatkom mreže. Iako će većina saobraćaja koji se generiše na klinici na njoj i biti terminiran, ipak se ne može zanemariti i komponenta odlaznog saobraćaja, jer su neki serveri značajni za poslovanje ustanove, predviđeni da budu u samoj kičmi mreže, kao što su mail, web serveri, ali i baze podataka. Pored toga, preko kičme mreže sve klinike ostvaruju i vezu sa Internetom i eventualno drugim klinikama $\mathrm{u}$ zemlji i inostranstvu. Zbog toga je predviđeno da ovaj link bude kapaciteta $2 \mathrm{~Gb} / \mathrm{s}$, odnosno realizovan je kao LAG od dva gigabitna linka. Na taj način nije postignuto samo povećanje kapaciteta, već i redundantnost ovog značajnog linka. Tako- 
đe, ovaj link treba realizovati optičkim vlaknima. Većini klinika dovoljan je jedan link ovog kapaciteta ka kičmi mreže, jer će se saobraćaj koji se generiše na mreži klinike uglavnom i terminirati na samoj klinici. Međutim, za dva organizaciona sistema VMA predviđa se implementacija dva ovakva linka ka kičmi mreže. To je slučaj instituta za radiologiju i instituta za medicinsku biohemiju (laboratorija). Ova dva sistema odstupaju od pravila da je interni saobraćaj veći od eksternog, jer će upravo druge klinike najviše pristupati serverima ovih sistema. Zbog tog će opterećenje ovih linkova biti veće, pa je potrebno i povećati nijhov kapacitet. Način na koji su ova dva linka povezana na kičmu, objašnjen je u opisu kičme mreže, a suština je da se, pored povećanog kapaciteta, omogući i redundantnost same veze, imajući u vidu njen značaj.

Pored ovih elemenata mreža može da sadrži i uređaje za bežični pristup, tj. wirless access points, koji omogućavaju implementaciju Wirless LAN-a u sistemu. To je bitno za korisnike notebook računara, kojima se na ovaj način omogućava povezivanje na mrežu bežično, čime se dobija na modularnosti mreže i mobilnosti.

Na kraju, na slici 1 naznačena je i IP kamera, čime se želi istaći ideja da se računarska mreža može uspešno upotrebiti za prenos slike. Živa slika koja se prenosi kroz računarsku mrežu može biti slika iz sistema nadzora objekta ili sistema nadzora bolesničkih soba. Pored toga, kroz računarsku mrežu može se prenositi slika iz operacione sale, čime se omogućava prenos toka neke operacije kroz mrežu, što je naročito značajno za VMA kao edukativnu i naučnoistraživačku ustanovu. Svi ovi sistemi prenosa slike sastoje se, u suštini, od dva dela. Jedan deo čine video serveri na koje se vezuju kamere, a drugi deo su računari na kojima se izvršavaju namenski softveri koji omogućavaju pristup video serverima i posmatranje sadržaja koji se snima. Implementacija ovih sistema zajedno sa realizacijom informacionih sistema klinika $\mathrm{i}$ informacionog sistema VMA u celini povećava stepen iskorišćenja mrežne infrastrukture, što povećava njenu isplativost.

\section{Kičma računarske mreže}

Kičma računarske mreže VMA prikazana je na slici 2. Ovaj deo mreže sastoji se od dva Layer 3 switcha, koja su međusobno povezana sa dva gigabitna linka. Ova veza može se ostvariti upotrebom optičkih kablova. Na dva switcha povezane su sve mreže organizacionih jedinica VMA, kao i centralni serveri u sistemu, web server, mail server i ruteri koji omogućavaju vezu računarske mreže VMA sa Internetom, javnom telefonskom mrežom i eventualno drugim klinikama u zemlji, inostranstvu, NATO-u, Partnerstvu za mir i mirovnim misijama, preko WAN linkova.

Layer 3 switchevi treba da zadovolje iste karakteristike kao i opisani switchevi i još:

- dovoljan broj gigabitnih portova na koje bi se povezale klinike i serveri sistema;

- Layer 3 funkcionalnost, uz implementaciju QoS, policy rouitinga, pristupnih lista, kao i podržavanje dinamičkih protokola rutiranja kao što je OSPF;

- kompatibilnost sa standardima 802 1.q i 802 1.p;

- SPT (Spanning Tree Protocol) po VLAN-u. Ovim protokolom sprečava se 
kruženje paketa kroz virtuelnu LAN mrežu, tako što se određuje samo jedan switch koji usmerava pakete;

- upravljivost, kompatibilnost sa SNMP protokolom.

S obzirom na to da se radi o kičmi jedne kompleksne i složene mreže, linkovi u ovom delu mreže definisani su tako da zadovolje dva osnovna kriterijuma: dovoljan kapacitet i redundantnost, jer se radi o temelju sistema, koji mora uvek da funkcioniše. Zbog toga je predložena šema veza u kičmi mreže kao na slici 2 .

Sve mreže klinika, instituta, administrativnih organa i drugih organizacionih sistema VMA, vezane su na ova dva switcha, linkovima kapaciteta $2 \mathrm{~Gb} / \mathrm{s}$, tj. pomoću LAG-a od dva gigabitna linka.
Svaka klinika vezana je ili na jedan ili na drugi switch. Na koji će se switch klinika vezivati zavisi od rastojanja i prostornog rasporeda klinika, ali je takođe bitno da se switchevi podjednako opterete. Podjednako opterećenje odnosi se prevashodno na saobraćajno opterećenje, a ne na to da podjednak broj klinika bude na oba servera. Neke mreže klinika generisaće više saobraćaja od drugih, pa o tome treba voditi računa. To je sada teško definisati, jer je potrebno poznavati preciznije karakteristike saobraćaja, ali se kasnije praćenjem saobraćaja na mreži može i odraditi prekonfiguracija.

Dve mreže odstupaju od ovog načina povezivanja. To su mreže Instituta za radiologiju i medicinsku biohemiju. $\mathrm{Za}$

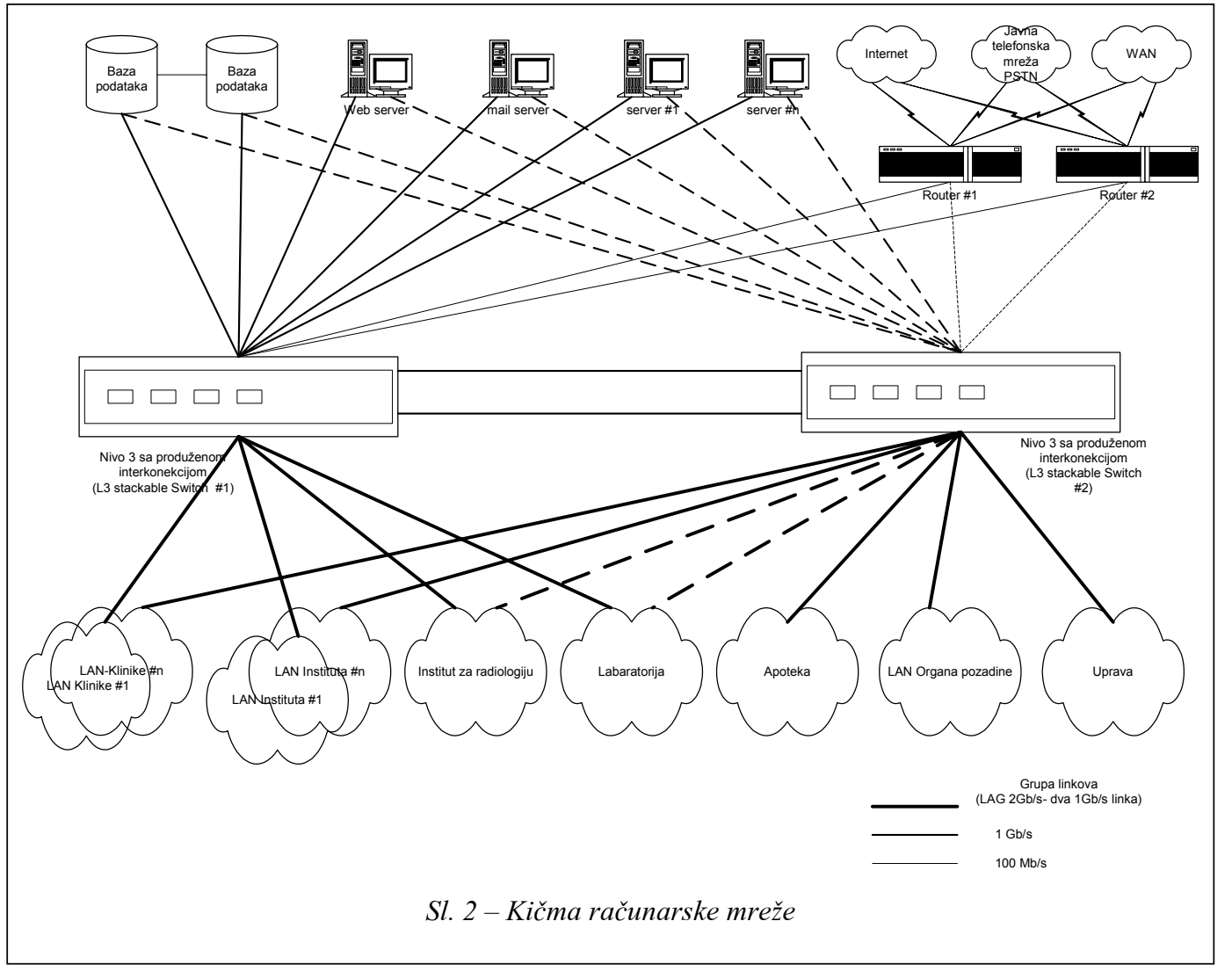


ove dve mreže karakteristično je da će generisati veliki eksterni saobraćaj, pa su linkovi ovih mreža ka kičmi povezani tako da se obezbedi dodatni kapacitet. Naime, svaka od ovih mreža vezana je na oba switcha, sa po $2 \mathrm{~Gb} / \mathrm{s}$, što daje ukupan kapacitet od $4 \mathrm{~Gb} / \mathrm{s}$. Ove dve veze podjednako se koriste ako su switchevi podjednako opterećeni, ali i jedna drugoj predstavljaju redundantnost.

Kao što se sa slike 2 vidi svaki od servera u sistemu povezan je sa oba switcha linkovima kapaciteta od $1 \mathrm{~Gb} / \mathrm{s}$, koji se mogu realizovati upotrebom optičkih kablova ili upotrebom UTP kablova, što zavisi od rastojanja između switcha i servera. Na taj način ostvaren je i dovoljan kapacitet serverskih veza, ali i njihova redundantnost. Naime, saobraćaj na server dolazi i po jednom i po drugom lin$\mathrm{ku}, \mathrm{u}$ zavisnosti od klinike sa koje potiče, kao i switcha na koji je povezana. U slučaju da dođe do oštećenja jednog od linkova, zbog veze između switcheva, saobraćaj će biti preusmeren na drugi switch, tako da sistem i dalje funkcioniše.

Ceo sistem može se povezati i sa drugim mrežama, pre svega na Internet ili sa mrežama drugih ustanova Vojske SCG, odnosno sa drugim klinikama ili institutima u zemlji, inostranstvu, NATO-u, Partnerstvu za mir i mirovnim misijama. U tu svrhu predviđena je ugradnja rutera u mrežu. Ruteri su vezani na switcheve $100 \mathrm{Mb} / \mathrm{s}$ vezama. Sa druge strane, svaki od rutera ima vezu na Internet mrežu, čime je ostvarena redundantnost Internet konekcije. Internet konekcija može se ostvariti upotrebom DSL tehnologije i veze sa nadređenim provajderom Internet usluga. Kapaciteti ovih linkova mogu biti do $2 \mathrm{Mb} / \mathrm{s}$. Obe veze na
Internetu mogu se istovremeno koristiti, odnosno saobraćaj se podjednako može usmeravati na jedan ili drugi link.

Pored ovih veza može se predvideti više WAN linkova ka drugim mrežama. Ovi linkovi mogu biti, takođe, realizovani upotrebom DSL tehnologije ili Frame Relay mreže Telekoma Srbije. Šta će biti korišćeno zavisi od konkretnog slučaja i geografskog rasporeda mreža sa kojima se ovo povezivanje ostvaruje. Na kraju, postoji i veza ka telefonskoj mreži, koja omogućava dial-in pristup na mrežu, tj. mogućnost da se zaposleni od kuće ili sa neke udaljene lokacije mogu vezivati na mrežu. Naravno, ove veze mogu se upotrebiti i za telefonski saobraćaj.

\section{Zaključak}

Polazeći od opštih karakteristika Vojnomedicinske akademije, njene organizacije i delatnosti kojom se bavi, u radu su prikazane smernice $u$ implementaciji računarske mreže VMA u Beogradu. Prikazana su rešenja realizacije dva nivoa mreže. U prvom delu rada prikazana je generalna realizacija računarskih mreža organizacionih jedinica VMA. Konkretne mreže klinika, instituta i drugih organizacionih jedinica VMA razlikovaće se, ali principi koji su ovde izloženi biće im zajednički. U drugom delu rada prikazano je konkretno rešenje realizacije mrežne kičme.

Literatura:

[1] (MSCE00) MSCE Training Kit-Microsoft Windows 2000.

[2] Network Infrastructure Administration, Microsoft Corporation, 2000.

[3] Komar, B.: TCP/IP, Kompjuter biblioteka, Čačak.

[4] (Cisco Press) Interconnecting Cisco Network Devices.

[5] Muller, S.: Nadogradnja i popravka PC, prevod, 8. izdanje, CET biblioteka, Beograd, 1998. 